\title{
Water Breakthrough Shape Description of Horizontal Wells in Bottom-Water Reservoir
}

\author{
Shijun Huang, ${ }^{1}$ Baoquan Zeng, ${ }^{2}$ Fenglan Zhao, ${ }^{3}$ Linsong Cheng, ${ }^{1}$ and Baojian Du ${ }^{1}$ \\ ${ }^{1}$ CMOE Key Laboratory of Petroleum Engineering, China University of Petroleum, Beijing 102249, China \\ ${ }^{2}$ Petrochina Research Institute of Petroleum Exploration \& Development, Beijing 102249, China \\ ${ }^{3}$ The EOR Center, China University of Petroleum, Beijing 102249, China \\ Correspondence should be addressed to Shijun Huang; fengyun7407@163.com
}

Received 25 May 2014; Accepted 11 August 2014; Published 30 September 2014

Academic Editor: Wei-Chiang Hong

Copyright (C) 2014 Shijun Huang et al. This is an open access article distributed under the Creative Commons Attribution License, which permits unrestricted use, distribution, and reproduction in any medium, provided the original work is properly cited.

Horizontal wells have been applied in bottom-water reservoir since their advantages were found on distribution of linear dropdown near wellbore, higher critical production, and more OOIP (original oil in place) controlled. In the paper, one 3D visible physical model of horizontal physical model is designed and built to simulate the water cresting process during the horizontal well producing and find water breakthrough point in homogenous and heterogeneous reservoir with bottom water. Water cresting shape and water cut of horizontal well in between homogenous and heterogeneous reservoir are compared on the base of experiment's result. The water cresting pattern of horizontal well in homogeneous reservoir can be summarized as "central breakthrough, lateral expansion, thorough flooding, and then flank uplifting." Furthermore, a simple analysis model of horizontal well in bottom water reservoir is established and water breakthrough point is analyzed. It can be drawn from the analysis result that whether or not to consider the top and bottom border, breakthrough would be located in the middle of horizontal segment with equal flow velocity distribution.

\section{Introduction}

In the 1990s, with wide application of Hele-Shaw model, 2-D (two-dimensional) physical experiment had been gradually used to investigate performance of horizontal wells in reservoirs with bottom water. Permadi's research showed that water cresting will first present at heel of horizontal segment; then it would gradually move toward to toe [1]; Souza established a new mathematical model to analyse water breakthrough time and flow regime after breakthrough with reservoir parameters, compared with that of numerical simulation by Eclipse, Jiang, Tove Aulie, Francols M, Giger and Wang et al. investigated the water cresting of horizontal well with the mathematical model above and got the similar conclusion [2-6].

Logarithmic pressure distribution of vertical well would result in higher pressure loss near wellbore than that of horizontal well [7]. Due to its particular contraction with reservoir, horizontal well has linear pressure distribution and low pressure loss near wellbore; the corresponding OWC (oilwater contract) would rise with cresting shaped. Therefore the horizontal wells have much lower pressure difference than that of vertical wells with the same production and its critical production is significantly greater than the vertical; on the other hand, the horizontal wells have larger OOIP and swept volume, higher cumulative oil production without water, and longer water free production period; all those would make its wide application in bottom-water reservoir.

At present, investigation on horizontal wells developing bottom water reservoir is not yet systematical due to complex wellbore structure. First, there are few literatures particularly describing water cresting process and detecting breakthrough location, which led to unreasonable completion design and undirected measures of water shutoff and water control; finally it is unfavorable for development of bottom water reservoir $[8,9]$. Second, performance and influence of 


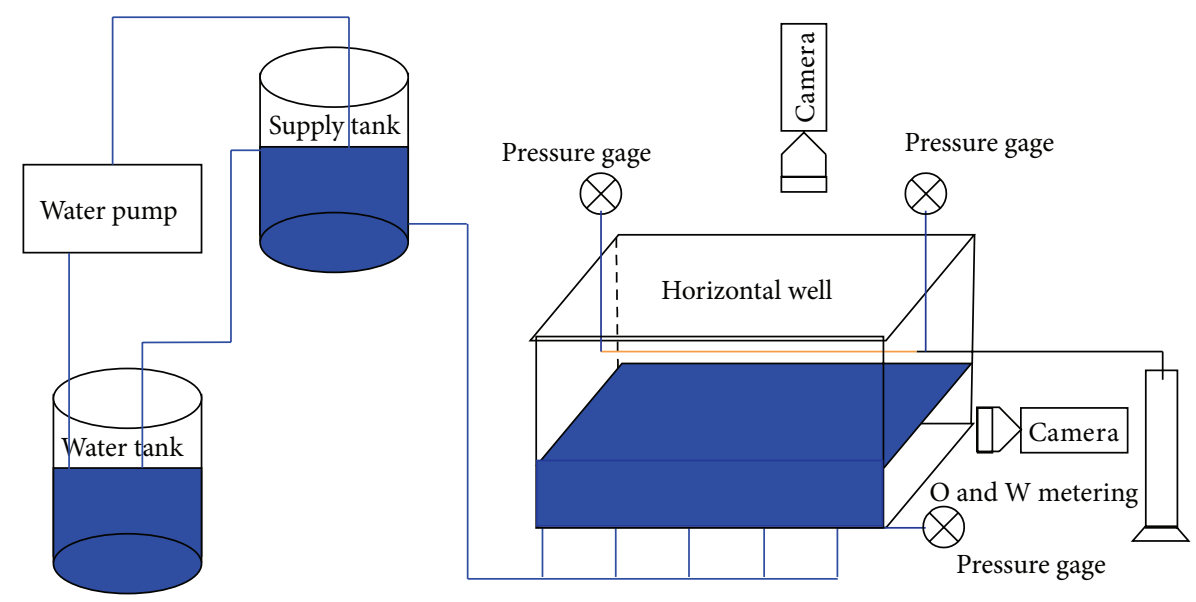

FIGURE 1: 3-D physical model of horizontal wells in bottom water reservoir.

horizontal wells had not been summarized systematically and the corresponding relationship between geology and performance has not yet been established.

In this paper, combined with numerical simulation and 3-D physical simulation, fluid mechanics in porous medium was used to investigate water cresting and breakthrough location, providing consistent theory for reasonable measures of water shutoff and water control.

\section{Water Cresting Experiment with Horizontal Well}

After heel-toe pressure difference of horizontal wells was calculated with coupling model [10], majority of reservoir engineers consider that lower pressure make the breakthrough location appear at the heel rather than at the toe. Moreover, P. Permadi's 2-D plate experiment verified this theory with photos of water cresting. Then, a lot of experimental results from Hele-Shaw model showed that heel-toe pressure differences have a significant influence on water cresting. In addition, Q. Jiang, Tove Aulie, Francols M, Giger, and Wang Jialu et al. investigated the water cresting of horizontal wells with similar physical model and got similar conclusion.

With extremely simplified formula; most scholars believe that water cresting would rise asymmetrically, and breakthrough would present at the heel [11]. However, the experimental model and parameters have not been scientifically demonstrated, and the results may be not coordinated with production data.

Firstly, 2-D model can only simulate piston-displacement in heterogeneous reservoir while ellipsoid pressure field cannot be simulated due to walls of device; therefore the water cresting simulated would have a large difference with the one in reservoir.

Secondly, the experiment devices without sand keep distance of two parallel glasses only $0.00625 \mathrm{~m}$ in order to increase flow resistance, and the obtained permeability about $32000 \mu \mathrm{m}^{2}\left(3.2 \times 10^{7} \mathrm{mD}\right)$ is not practical.
If the flow velocity gets to a certain value, both viscous resistance and inertial resistance are generated; meanwhile nonlinear relationship would present between flow velocity and pressure difference, and the flow velocity was defined as critical velocity for Darcy's law. Reynolds criterion was used by Katja Hof to calculate the critical flow velocity [12]:

$$
v_{c}=\frac{3.5 \mu \phi^{2 / 3}}{\rho \sqrt{K}} .
$$

As mentioned in literature the lowest average velocity of experiments is $7.04 \times 10^{-3} \mathrm{~m} / \mathrm{s}$, which is much higher than critical velocity of $1.66 \times 10^{-3} \mathrm{~m} / \mathrm{s}$ from a certain reservoir and is not coordinate with flow velocity in porous media. Without sand, Hele-Shaw mode has extremely high permeability and nearly no flow resistant for bottom water. As a result, generation as well as development of water cresting has no practical significance in that model.

Rather than 2-D model, 3-D physical model had been carried out successively to accurately simulated reservoir parameters, to reflect inflow performance of horizontal wells with different completions, and to better analyze influence factors of well productivity; therefore, a new device was designed to investigate water cresting shape and to detect breakthrough location in Figure 1.

2.1. Water Cresting Formation and Development. As shown in Figure 2, water cresting formation and development can be investigated with pictures at the time of beginning, water breakthrough, and watercut about $40 \%, 60 \%, 90 \%$, in which horizontal segment length is $7 \mathrm{~cm}, 14 \mathrm{~cm}$, and $21 \mathrm{~cm}$ separately. And several typical water cresting types of horizontal wells were obtained from experimental results above in homogeneous reservoir, with the same watercut, horizontal segment about $7 \mathrm{~cm}$ had much more severe OWC deformation, more remaining oil at two flanks of water cresting, while OWC of horizontal segment about $21 \mathrm{~cm}$ is relatively flat.

Throughout the whole process, flat OWC will rise steady firstly; then it was gradually deformed into water cresting 

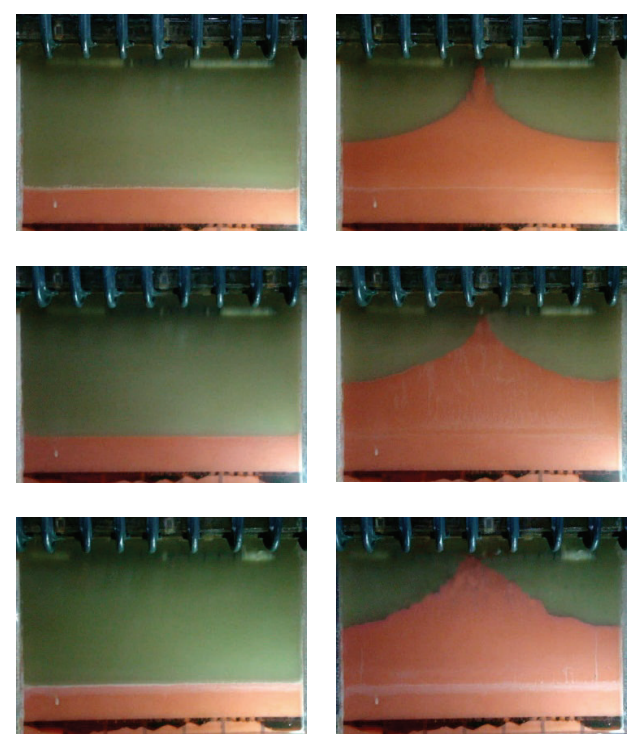

The beginning

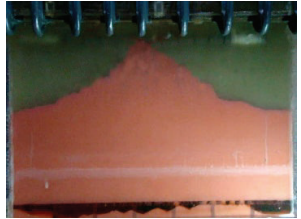

Water breakthrough
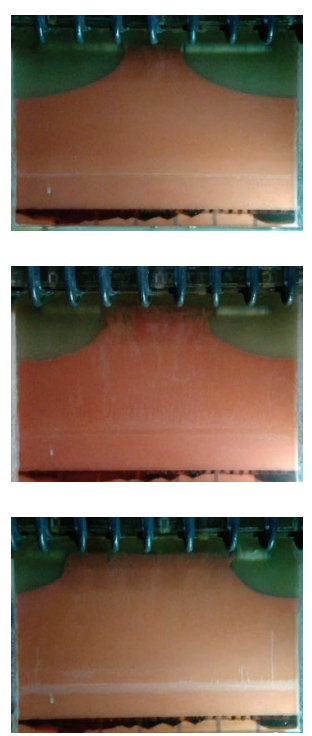

Watercut of $40 \%$
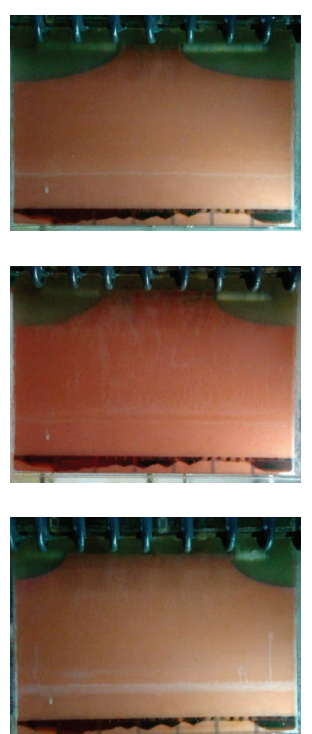

Watercut of $60 \%$
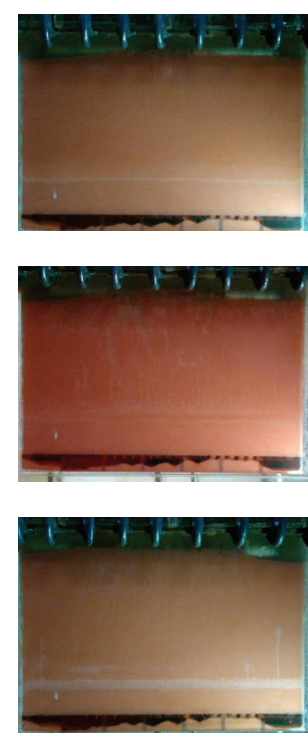

Watercut of $90 \%$

FIGURE 2: The formation and development of water cresting with different horizontal segment length.

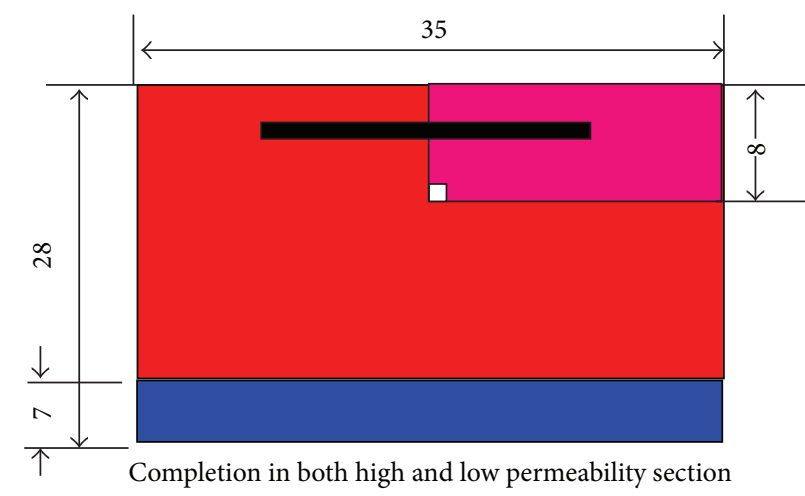

(a)

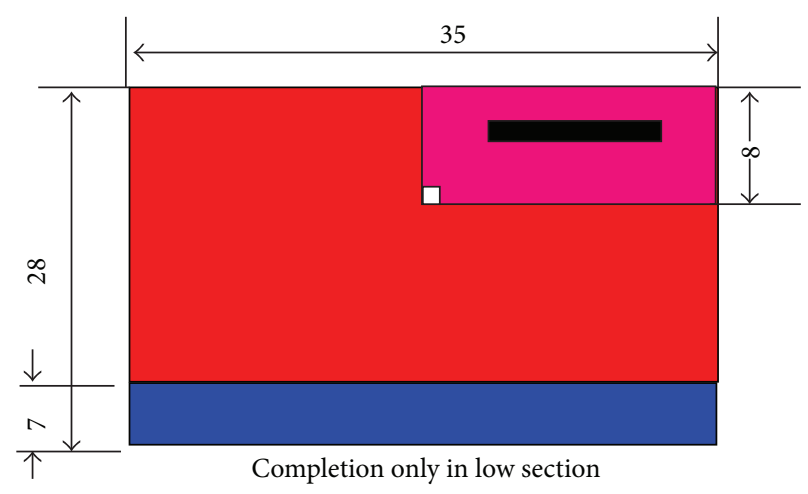

(b)

FIgURE 3: Physical models with different horizontal segment length.

and breakthrough at the middle of horizontal well; finally the length of water cresting would extended along the horizontal segment from the middle to the toe and the heel until the whole segment was flooded.

\subsection{Water Cresting Shape in Heterogeneous Reservoirs. Two} physical models with different horizontal segment length were designed (Figure 3 ) to analyze water cresting shape in heterogeneous reservoir. In each model, there are two areas with permeability of $10.11 \mu \mathrm{m}^{2}$ and $2.33 \mu \mathrm{m}^{2}$ separately along horizontal segment, and permeability contrast is almost 4 times. In the first one, the horizontal segment about $14 \mathrm{~cm}$ was perforated in both areas; in the second one, the horizontal segment length of $7 \mathrm{~cm}$ was only located and performed in low permeability area.

In the first model (Figure 4), bottom water was advanced so sharply in high permeability area that lower permeability area would not be flooded and be rich of banded remaining oil, which is similar to "eaves oil" with bowl shaped because there is nearly no pressure difference as well as no production in low permeability area; therefore this is the main reason why production of horizontal well in reservoir is much lower than theoretical one. The water cresting process can be described as follows: tilted advancing $\rightarrow$ high permeability raise $\rightarrow$ high permeability flooded $\rightarrow$ flank uplift $\rightarrow$ no flooding in low permeability; experimental results showed that if permeability contrast is larger than a certain value, there would be much remaining oil in low permeability area and "eaves oil," which would become new targets of potential tapping in high watercut stage.

In the second model (Figure 4), the bottom water always advanced steadily without water cresting before it got to low permeability area. The low permeability area was flooded without banded remaining oil in its lower part. However, throughout the whole production high permeability area had 


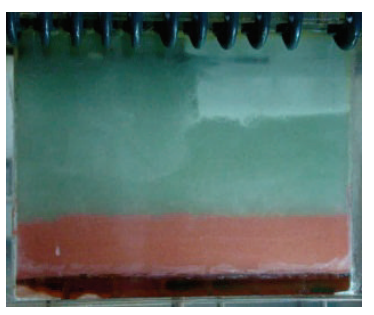

Initial

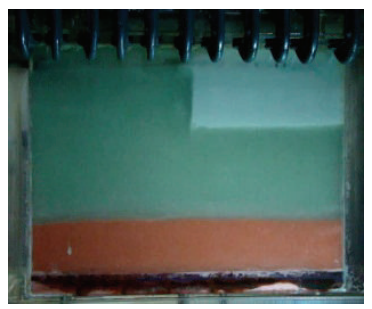

Initial

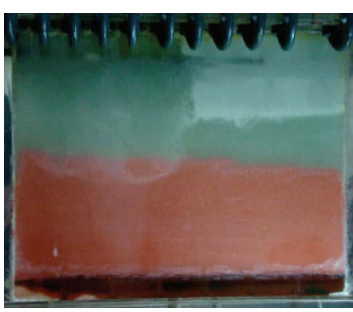

Cresting

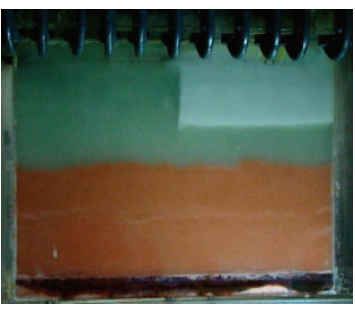

Cresting

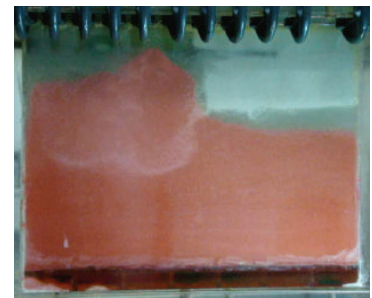

Water flow from high permeability zone

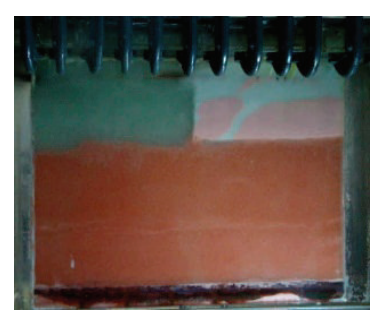

Water flow from Low permeability zone

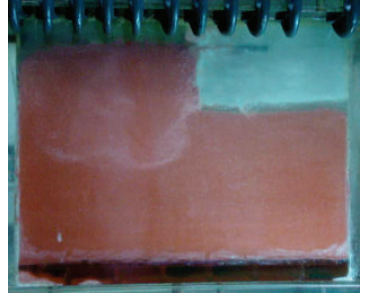

$f_{w}=90 \%$

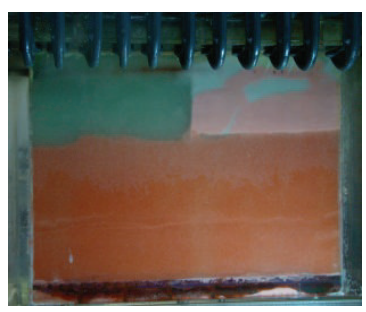

$f_{w}=90 \%$

FIGURE 4: The formation and development of water cresting with low and high permeability section.

no water flooding while low permeability area had been flooded with scattered remaining oil. And that phenomenon is much coordinated with displacement characteristics in low permeability reservoir.

Permeability heterogeneity had distinguished impact on watercut, rising step by step, and the number of steps was coordinate with number of nonconsecutive high permeability areas covered by horizontal segment.

To better investigate coupling effect between flow in reservoir and variable mass flow in wellbore, a new model was established to analyze the water cresting with different parameters.

\section{Theoretical Investigation on Water Cresting}

3.1. Horizontal Well with $(2 n+1)$ Perforation. As shown in Figure 5, coordinates of perforations are $(0,0),( \pm a, 0)$, $( \pm 2 a, 0), \ldots,( \pm n a, 0)$, and longitudinal velocity at any point is as follows:

$$
\begin{aligned}
& v_{y}= v_{y_{0}}+v_{y_{1}}+v_{y_{1^{\prime}}}+\cdots+v_{y_{n}}+v_{y_{n^{\prime}}} \\
&=-\frac{\partial \Phi_{0}}{\partial y}-\frac{\partial \Phi_{1}}{\partial y}-\frac{\partial \Phi_{1^{\prime}}}{\partial y}-\cdots-\frac{\partial \Phi_{n}}{\partial y}-\frac{\partial \Phi_{n^{\prime}}}{\partial y} \\
&= \frac{q}{\pi} y\left[\frac{1}{x^{2}+y^{2}}+\frac{1}{(x+a)^{2}+y^{2}}+\frac{1}{(x-a)^{2}+y^{2}}\right. \\
&\left.+\cdots+\frac{1}{(x+n a)^{2}+y^{2}}+\frac{1}{(x-n a)^{2}+y^{2}}\right], \\
&\left.v_{y}\right|_{x=0, y=y_{0}}=\frac{q}{\pi} y_{0}\left[\frac{1}{y_{0}^{2}}+\frac{2}{a^{2}+y_{0}^{2}}+\cdots+\frac{2}{(n a)^{2}+y_{0}^{2}}\right] \\
&=\frac{q}{\pi} y_{0}\left[\sum_{i=0}^{n} \frac{1}{i^{2} a^{2}+y_{0}^{2}}+\sum_{i=1}^{n} \frac{1}{i^{2} a^{2}+y_{0}^{2}}\right],
\end{aligned}
$$

$$
\begin{aligned}
\left.v_{y}\right|_{x=j a, y=y_{0}=\frac{q}{\pi} y_{0}[} \frac{1}{(j a)^{2}+y_{0}^{2}}+\frac{1}{(j+1)^{2} a^{2}+y_{0}^{2}} \\
+\frac{1}{(j-1)^{2} a^{2}+y_{0}^{2}} \\
+\cdots+\frac{1}{(n+j)^{2} a^{2}+y_{0}^{2}} \\
\left.+\frac{1}{(n-j)^{2} a^{2}+y_{0}^{2}}\right] \\
=\frac{q}{\pi} y_{0}\left[\sum_{i=0}^{n} \frac{1}{i^{2} a^{2}+y_{0}^{2}}+\sum_{i=n}^{2 n+1} \frac{1}{i^{2} a^{2}+y_{0}^{2}}\right], \\
\left.v_{y}\right|_{x=0, y=y_{0}}>\left.v_{y}\right|_{x=j a, y=y_{0}} \cdot
\end{aligned}
$$

The longitudinal velocity of middle perforation is always the highest, and the water cresting shape was shown in Figure 5 (right).

When $n \rightarrow+\infty$ and $a \rightarrow 0$, it was equal to a horizontal well with barefoot completion, and breakthrough point would be located in the middle of horizontal segment considering no pressure loss.

3.2. Water Cresting with Top and Bottom Boundary. Physical model shown in Figure 6 had a closed upper boundary and lower boundary with constant pressure. And the horizontal well can be considered as a row of $(2 n+1)$ wells with the same flow velocity. Based on image theory, in infinite space each perforation can be mapped to well array with an interaction of two injections and two productions. All wells can be divided 

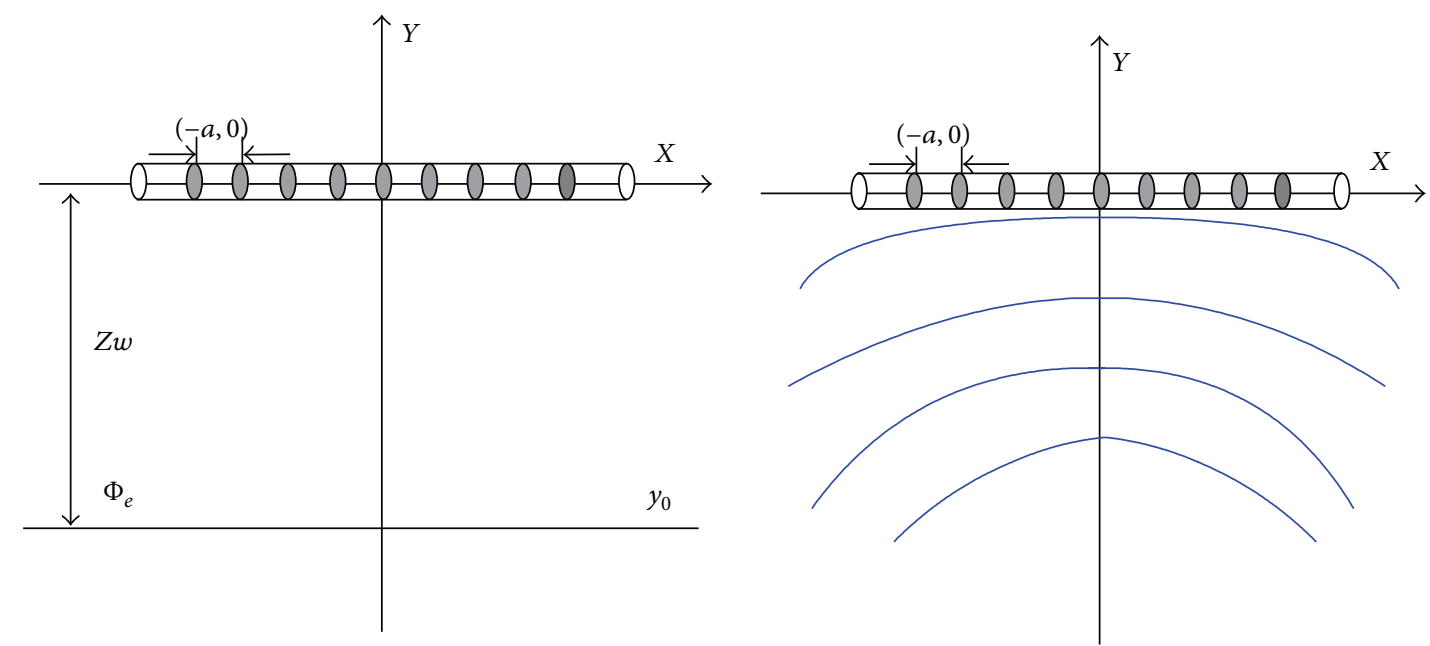

FIGURE 5: Crest schematic chart of horizontal wells with $(2 n+1)$ perforations.

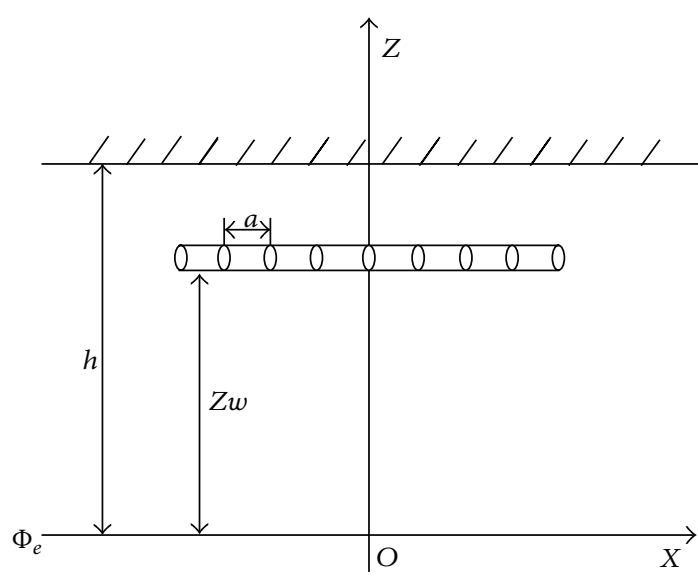

FIgure 6: Physical model of horizontal wells in bottom water reservoir (with upper and lower boundaries).

into four categories: (1) injection well with coordination of $(i a, 2 h+4 n h+Z w) ;(2)$ injection well with coordination of $(i a, 4 n h-Z w)$; (3) production well with coordination of (ia, $2 h+4 n h-Z w)$, and (4) production well with coordination of $(i a, 4 n h+Z w)$, where $i=0, \pm 1, \pm 2, \ldots, \pm n$,

$$
\begin{aligned}
& \Phi(x, z) \\
& =\frac{q}{2} \\
& \quad \times \sum_{-\infty}^{+\infty} \ln \left(\left(\left[(x-i a)^{2}+(Z-2 h-4 n h+Z w)^{2}\right]\right.\right. \\
& \left.\quad \times\left[(x-i a)^{2}+(Z-4 n h-Z w)^{2}\right]\right) \\
& \quad \times\left(\left[(x-i a)^{2}+(Z-2 h-4 n h-Z w)^{2}\right]\right. \\
& \left.\left.\quad \times\left[(x-i a)^{2}+(Z-4 n h+Z w)^{2}\right]\right)^{-1}\right)
\end{aligned}
$$

With Behçet formula, (3) can be transformed into

$$
\begin{aligned}
& \Phi(x, z) \\
& =\frac{q}{2} \ln \left(\left(\left[\operatorname{ch} \frac{\pi(x-i a)}{2 h}+\cos \frac{\pi(Z+Z w)}{2 h}\right]\right.\right. \\
& \left.\times\left[\operatorname{ch} \frac{\pi(x-i a)}{2 h}-\cos \frac{\pi(Z-Z w)}{2 h}\right]\right) \\
& \times\left(\left[\operatorname{ch} \frac{\pi(x-i a)}{2 h}+\cos \frac{\pi(Z-Z w)}{2 h}\right]\right. \\
& \left.\left.\quad \times\left[\operatorname{ch} \frac{\pi(x-i a)}{2 h}-\cos \frac{\pi(Z+Z w)}{2 h}\right]\right)^{-1}\right)
\end{aligned}
$$

$+C$

Therefore, longitudinal velocity would be

$$
\begin{aligned}
& V z \\
& =-\frac{\partial \Phi(x, z)}{\partial z} \\
& =\frac{\pi q}{2 h} \\
& \quad \times\left[\sin \frac{\pi(Z+Z w)}{2 h}\right. \\
& \quad+\frac{\operatorname{ch}((\pi(x-i a)) / 2 h)}{\operatorname{ch}((\pi(x-i a)) / 2 h)-\cos ^{2}((\pi(Z+Z w)) / 2 h)} \\
& \quad+\sin \frac{\pi(Z w-Z)}{2 h} \\
& \left.\quad \cdot \frac{\operatorname{ch}((\pi(x-i a)) / 2 h)}{c^{2}((\pi(x-i a)) / 2 h)-\cos ^{2}((\pi(Z w-Z)) / 2 h)}\right] .
\end{aligned}
$$


According to superposition principle, the longitudinal velocity of point $(x, z)$ superimposed by all perforations can be

$$
\begin{aligned}
& V z \\
& =\frac{\pi q}{2 h} \\
& \quad \times\left[\sin \frac{\pi(Z+Z w)}{2 h}\right. \\
& \quad \sum_{-n}^{n} \frac{c h((\pi(x-i a)) / 2 h)}{c h^{2}((\pi(x-i a)) / 2 h)-\cos ^{2}((\pi(Z+Z w)) / 2 h)} \\
& \quad+\sin \frac{\pi(Z w-Z)}{2 h} \\
& \left.\quad \cdot \sum_{-n}^{n} \frac{c h((\pi(x-i a)) / 2 h)}{\operatorname{ch}^{2}((\pi(x-i a)) / 2 h)-\cos ^{2}((\pi(Z w-Z)) / 2 h)}\right], \\
& R_{1}(x)=\frac{c h((\pi(x-i a)) / 2 h)}{c h^{2}((\pi(x-i a)) / 2 h)-\cos ^{2}((\pi(Z+Z w)) / 2 h)}, \\
& R_{2}(x)=\frac{c h((\pi(x-i a)) / 2 h)}{c h^{2}((\pi(x-i a)) / 2 h)-\cos ^{2}((\pi(Z w-Z)) / 2 h)} .
\end{aligned}
$$

It could be proved that $R$ is monotone decreasing function of $x$ :

$$
\begin{aligned}
&\left.V z\right|_{(m a, z)}-\left.V z\right|_{(0, z)} \\
&=\frac{\pi q}{2 h}\left\{\sin \frac{\pi(Z+Z w)}{2 h}\right. \\
& \times\left[R_{1}(n a+|m| a)\right. \\
& \quad-R_{1}(n a)+R_{1}(n a+|m| a-a) \\
& \quad-R_{1}(n a-a)+\cdots+R_{1}(n a+a) \\
&\left.\quad-R_{1}(n a-|m| a+a)\right] \\
&+\sin \frac{\pi(Z w-Z)}{2 h} \\
& \times\left[R_{2}(n a+|m| a)-R_{2}(n a)\right. \\
&+R_{2}(n a+|m| a-a)-R_{2}(n a-a) \\
&+\cdots+R_{2}(n a+a) \\
&\left.\left.\quad R_{2}(n a-|m| a+a)\right]\right\}
\end{aligned}
$$

While $\sin ((\pi(Z+Z w)) / 2 h)>0, \sin ((\pi(Z w-Z)) / 2 h)>$ 0 , and $\left.V z\right|_{(m a, z)}-\left.V z\right|_{(0, z)}<0$, therefore, the middle one would have the highest longitudinal velocity and earliest water breakthrough with equal velocity at any perforation.

\section{Water Cresting with Inhomogeneous Flow with Top and Bottom Boundary}

Due to influence of supply area, permeability, reservoir damage, perforation density, flow velocity at any point of horizontal segment is usually unequal. Meanwhile the water cresting shape was carried out with different flow velocity at different nodes.

For different flow velocity at different perforation, (7) would be

$$
\begin{aligned}
& V z \\
& =\frac{\pi}{2 h} \\
& \quad \times\left[\sin \frac{\pi(Z+Z w)}{2 h}\right. \\
& \quad \sum_{-n}^{n} q_{i} \frac{\operatorname{ch}((\pi(x-i a)) / 2 h)}{c h^{2}((\pi(x-i a)) / 2 h)-\cos ^{2}((\pi(Z+Z w)) / 2 h)} \\
& \quad+\sin \frac{\pi(Z w-Z)}{2 h} \\
& \left.\quad \sum_{-n}^{n} q_{i} \frac{\operatorname{ch}((\pi(x-i a)) / 2 h)}{\operatorname{ch}^{2}((\pi(x-i a)) / 2 h)-\cos ^{2}((\pi(Z w-Z)) / 2 h)}\right],
\end{aligned}
$$

where $q_{i}$ is the flow velocity of perforation $i$.

In this model, inputting node number and flow velocity of each node, longitudinal velocity of any point below perforations could be calculated with equal (7), and the results would be carried out with a certain interval, until the highest point of water cresting reached the horizontal segment, and OWC at different time will form water resting.

As a result, the water cresting can be calculated with variable nodes and arbitrary flow velocity distribution considering the top and bottom boundaries.

Supposed that, reservoir thickness $-30 \mathrm{~m}$, height of water avoidance-25 m, horizontal segment length-300 m with 61 nodes evenly. In $(x, z)$ coordinate plane, calculated with equal (8), the longitudinal velocity at any point is the sum of $z$ partial derivatives for potential superimposed and longitudinal displacement is product of longitudinal velocity and time step. Figures 1-8 showed the water cresting shape with different flow velocity distribution. The production of each node in each fig were $[1,1, \ldots, 1],[4,1,1, \ldots, 1,1,4],[3,2,1,1, \ldots, 1,1,2,3]$, respectively.

Calculated results (Figure 7) showed that breakthrough would firstly present in the middle of horizontal well with equal flow velocity even though the velocity at heel or at toe is 4 times that of other points.

In order to investigate water cresting shape with different velocity distribution, the whole wellbore was simplified as five perforations supposing breakthrough time as $T$ and taking water cresting shape into comparison at $T / 5,3 T / 5$, and $T$. 

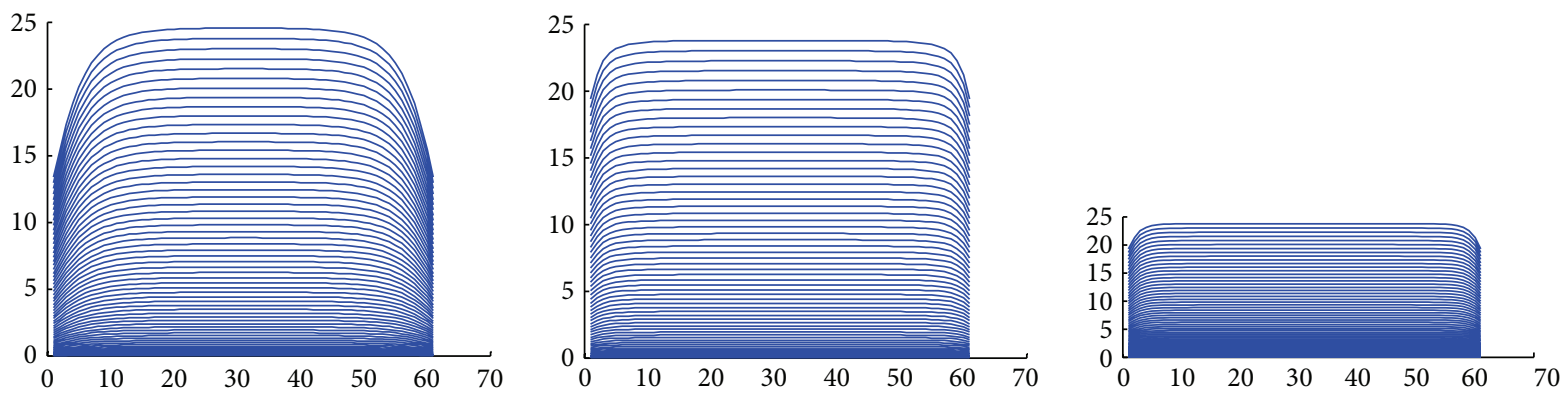

FIGURE 7: Crest rising shapes with different flow velocity distributions.
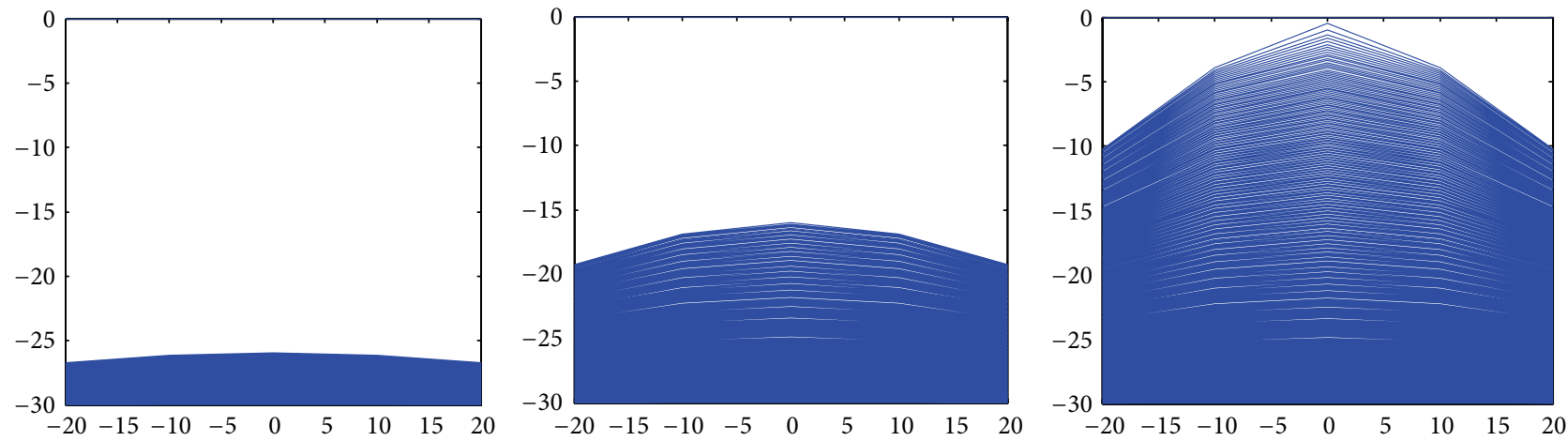

FIGURE 8: Crest rising shapes with equal inflow velocity.

When $\left[n_{1}, n_{2}, n_{3}, n_{4}, n_{5}\right]=[1,1,1,1,1]$, keeping the dimensionless total flow rate of 305 , the breakthrough time was $1706 \Delta t$, and water cresting shape was showed in Figure 8.

When $\left[n_{1}, n_{2}, n_{3}, n_{4}, n_{5}\right]=[10,8,5,2,1]$, namely, decreasing flow velocity, the dimensionless breakthrough time was $1445 \Delta t$, and water cresting shape was as shown in Figure 9.

The water cresting (Figure 9) showed that breakthrough would usually locate in the middle of horizontal segment rather than the point with high flow velocity for superposed pressure field.

When $\left[n_{1}, n_{2}, n_{3}, n_{4}, n_{5}\right]=[1,2,5,2,1]$, namely, central high-flank low, the dimensionless breakthrough time was $1371 \Delta t$, and water cresting shape was as in Figure 10.

When $\left[n_{1}, n_{2}, n_{3}, n_{4}, n_{5}\right]=[5,2,1,2,5]$, namely, central low-flank high, the dimensionless breakthrough time is $1951 \Delta t$, and water cresting shape was showed in Figure 11.

When $\left[n_{1}, n_{2}, n_{3}, n_{4}, n_{5}\right]=[25,1,5,1,10]$, namely, highlow-secondary high, the dimensionless breakthrough time is $1511 \Delta t$, and water cresting shape was shown in Figure 12.

With comparison of flow velocity distribution above, conclusions were obtained.

(1) For horizontal wells in bottom water reservoir, breakthrough would be usually located in the middle of horizontal segment rather than the point with high flow velocity.

(2) If its middle part was located in high permeability area and was perforated, horizontal well would have shorter water free production period and smaller water free production. Therefore we should pay much more attention to completion and water shutoff.

(3) Permeability distribution pattern of "central highflank low" would result in longer water free period and more production without water.

\section{Conclusion}

(1) With 3-D visible physical experiments, water cresting in homogeneous reservoir was "central breakthrough $\rightarrow$ lateral expansion $\rightarrow$ thorough flooding $\rightarrow$ flank uplifting."

(2) All water cresting shapes are almost similar at the same watercut for horizontal wells with different length. In preceding development, higher drawdown would result in steeper water cresting and much more severe fingering. While watercut $>90 \%$, the whole OWC would arrive at horizontal well.

(3) Whether or not to consider the top and bottom border, breakthrough would be located in the middle of horizontal segment with equal flow velocity distribution. To some extent, velocity distribution will have some influence on watercut trend, even though the velocity at heel or at toe is 4 times that of other points; breakthrough point would be still located in the middle of horizontal segment with rich remaining oil in flanks of water cresting. Therefore, for horizontal wells in the bottom water reservoir, 

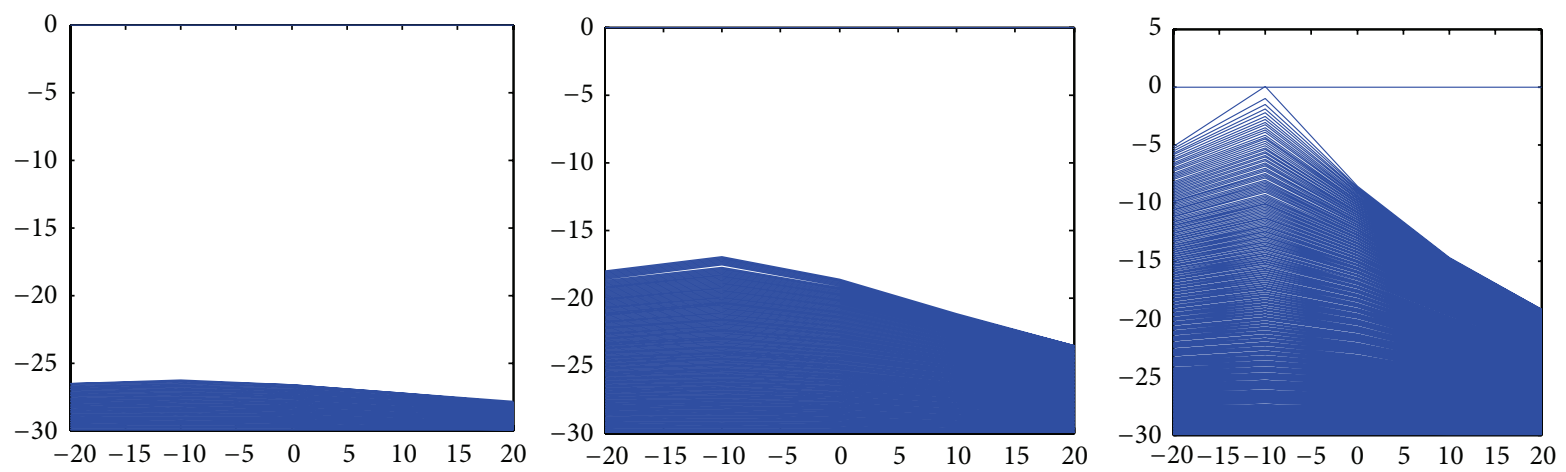

FIGURE 9: Crest rising shapes with declining inflow velocity from heel to toe.
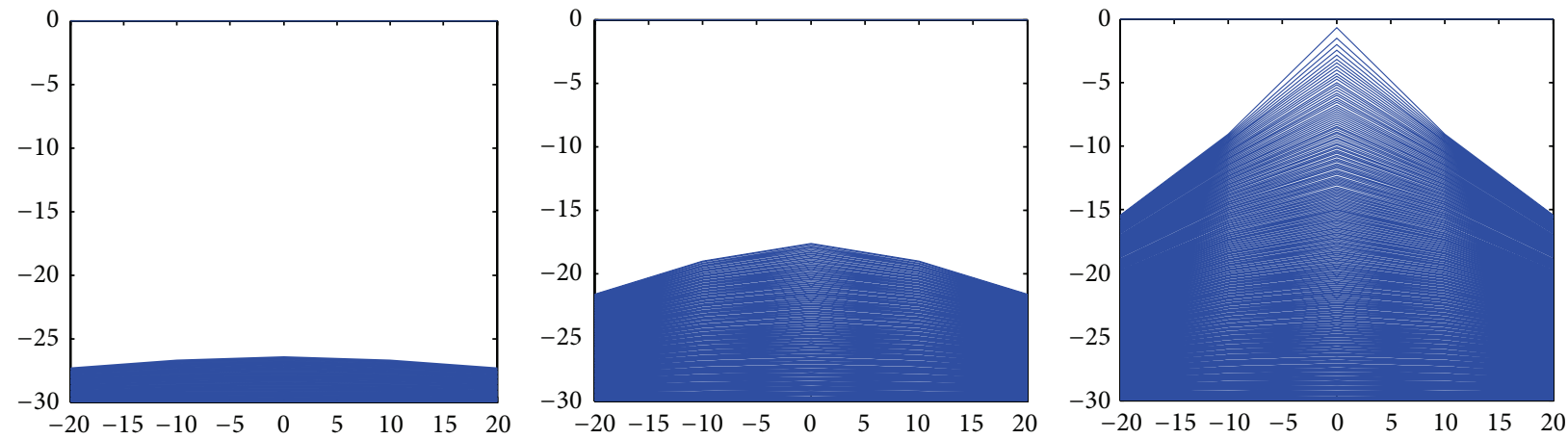

Figure 10: Crest rising shapes with inflow velocity of $[1,2,5,2,1]$ from heel to toe.
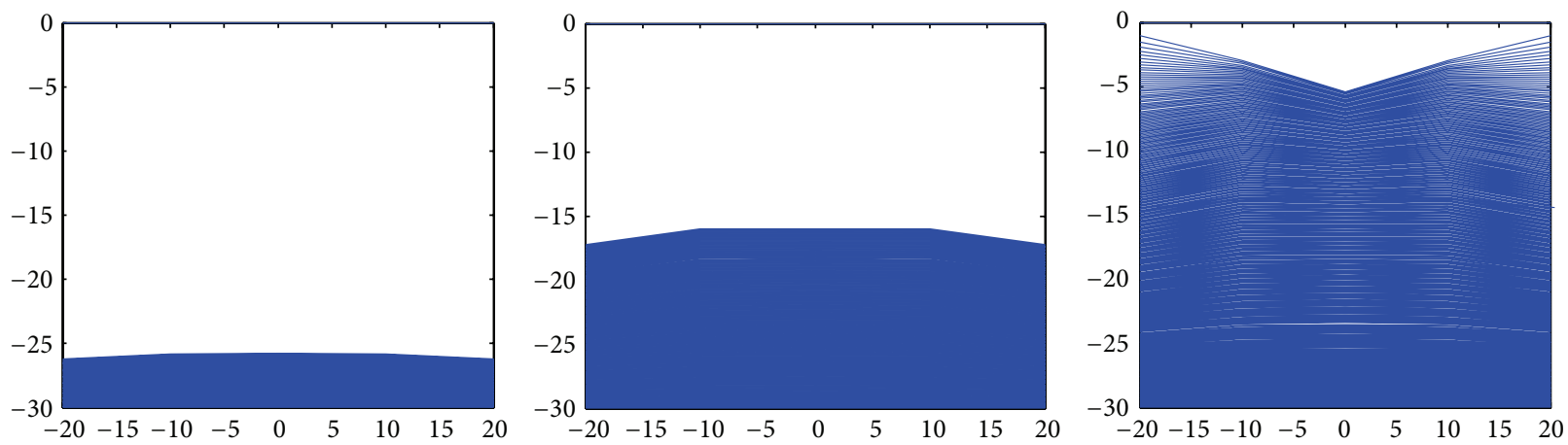

FIGURE 11: Crest rising shapes with inflow velocity of $[5,2,1,2,5]$ from heel to toe.
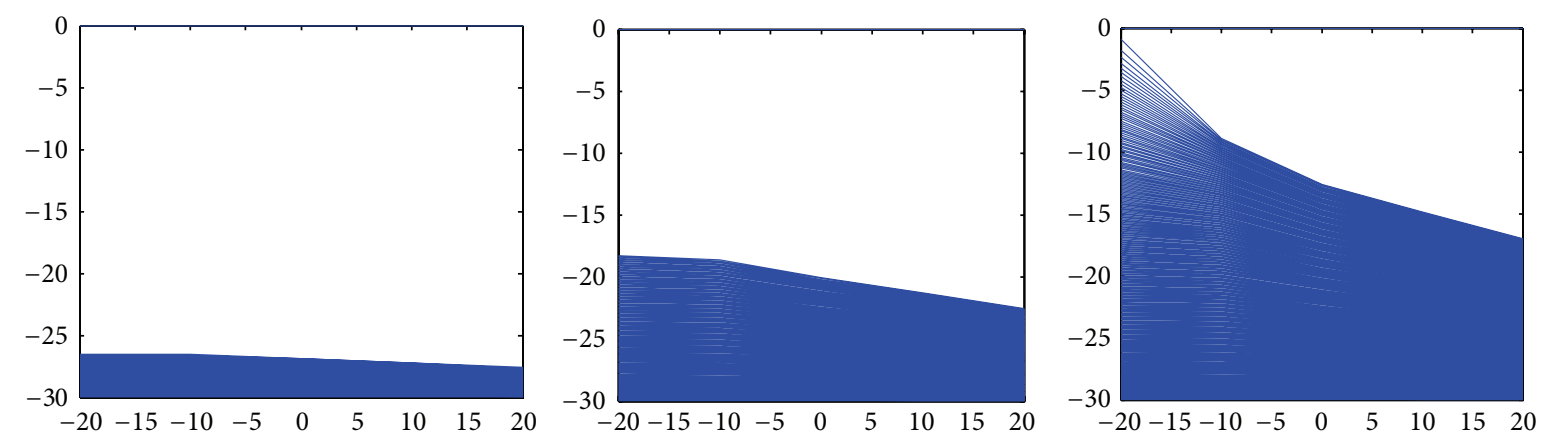

Figure 12: Crest rising shapes with inflow velocity of $[25,1,5,1,10]$ from heel to toe. 
bottom water will breakthrough not at the point with higher flow velocity but at the middle of horizontal segment for superposed pressure field.

\section{Conflict of Interests}

The authors declare that there is no conflict of interests regarding the publication of this paper.

\section{References}

[1] P. Permadi, R. L. Lee, and R. S. T. Kartoatmodjo, "Behavior of water cresting under horizontal well,” SPE30374, 1995.

[2] A. L. S. Souza, S. Arbabi, and K. Aziz, "A practical procedure to predict cresting behavior in horizontal well," SPE39063, 1997.

[3] Q. Jiang and R. M. Butler, "Experimental and numerical modelling of bottom water coning to a horizontal well," Journal of Canadian Petroleum Technology, vol. 37, no. 10, pp. 82-91, 1998.

[4] T. Aulie, H. Asheim, P. Oudeman, and P. Laboratorium, "Experimental investigation of cresting and critical flow rate of horizontal wells," SPE26639, 1995.

[5] F. M. Giger, "Analytic two-dimensional models of water cresting before breakthrough for horizontal wells," SPE Reservoir Engineering, vol. 4, no. 4, pp. 409-15378, 1989.

[6] J.-L. Wang, Y.-Z. Liu, and R.-Y. Jiang, "2-D physical modeling of water coning of horizontal well production in bottom water driving reservoirs," Petroleum Exploration and Development, vol. 34, no. 5, pp. 590-593, 2007.

[7] W. Renfu, Horizontal Well Production Technology of Different Type Reservoir in China, Petroleum Industry Press, Beijing, China, 1998.

[8] L. Hongshan and W. Shuqiang, "Study on variable density perforation tech for bottom-water reservoir of horizontal well," Well Testing, vol. 17, no. 3, pp. 42-77, 2008.

[9] M. Hongxia, C. Dechun, H. Huirong et al., "Optimization of well completion project for the selectively perforated horizontal well," Petroleum Geology and Recovery Efficiency, vol. 14, no. 5, pp. 84-87, 2007.

[10] B. J. Dikken, "Pressure drop in horizontal wells and its effect on their production performance," SPE 19824, 1989.

[11] C. Linsong, L. Zhaoxin, and Z. Lihua, "Reservoir engineering problem of horizontal wells coning in bottom-water driven reservoir," Journal of the University of Petroleum, vol. 18, no. 4, pp. 43-46, 1994.

[12] Y. Shenglai, Petrophsics, Petroleum Industry Press, Beijing, China, 2004. 


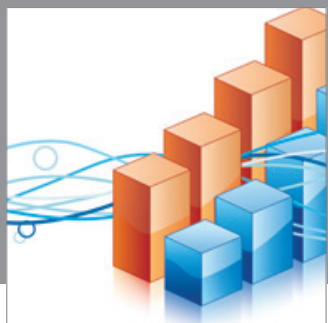

Advances in

Operations Research

mansans

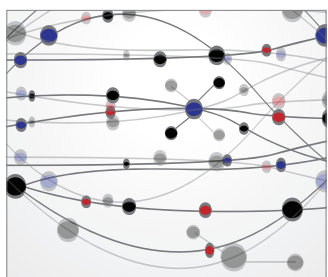

The Scientific World Journal
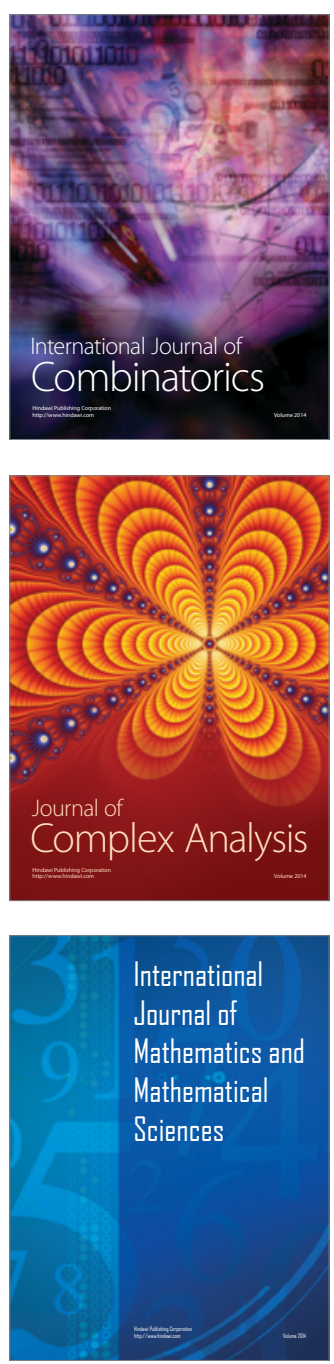
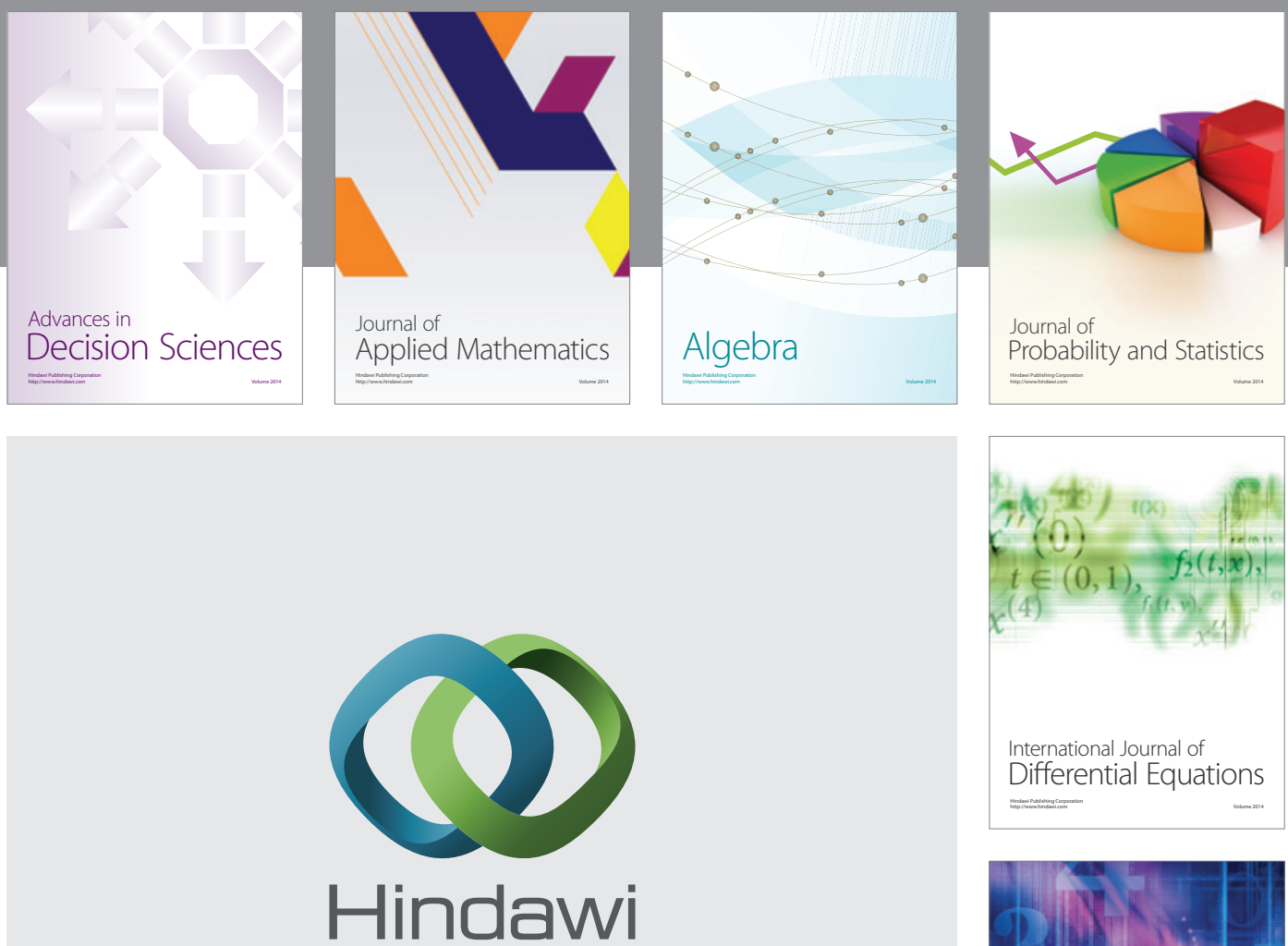

Submit your manuscripts at http://www.hindawi.com
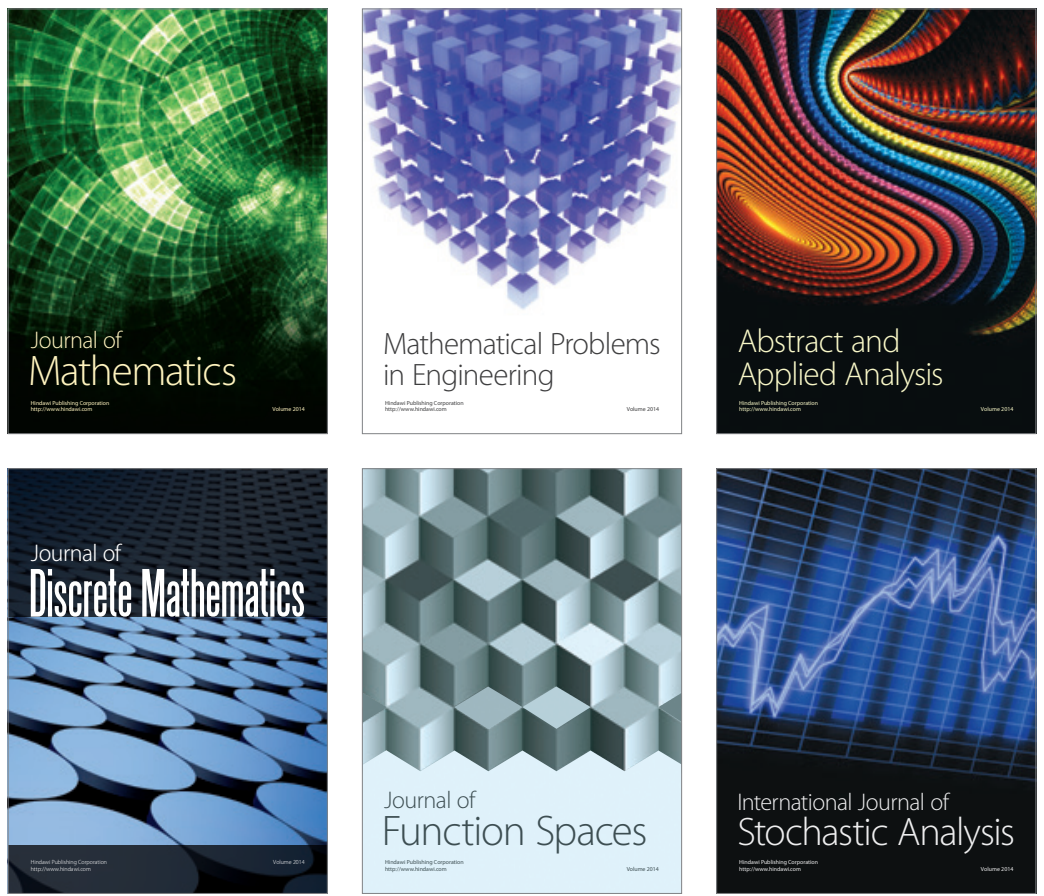

Journal of

Function Spaces

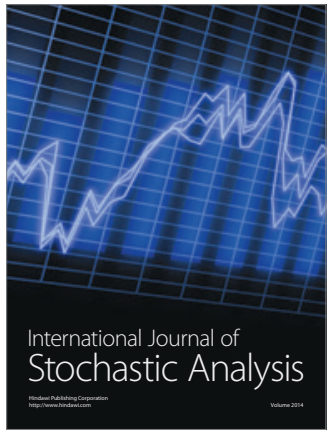

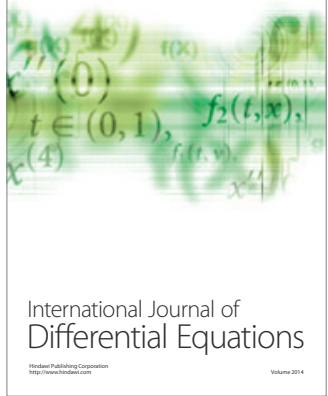
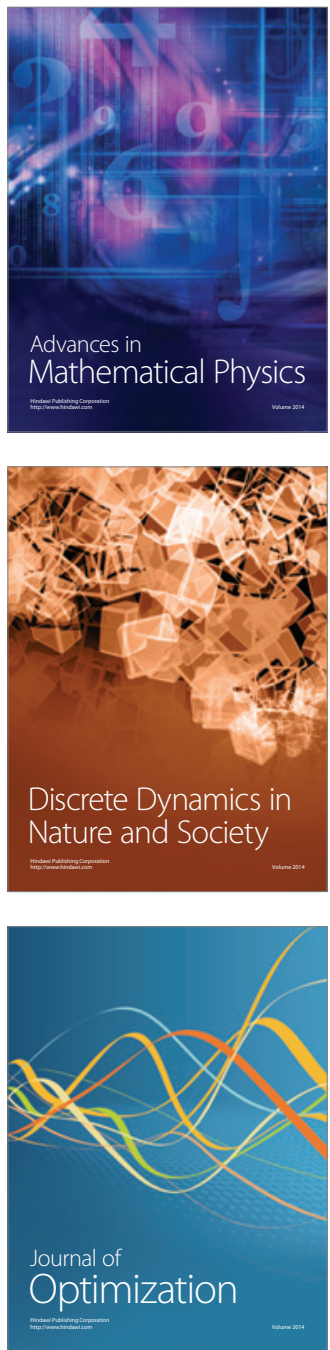